\title{
Mapping the Intangibilities of the Historic Centre of Porto: ParticipA(C)TION (and its Challenges) in Cultural Mapping Projects
}

\author{
Patrícia Romeiro \\ Centro de Estudos de Geografia e Ordenamento do Território (CEGOT) \\ University of Porto, Portugal
}

\begin{abstract}
This article focuses on cultural mapping projects as a strategy for urban development. In particular, it analyzes how one of the most important cultural mapping matrices - its participatory mission - can be operationalized. Moving away from other projects where participation is merely rhetoric or is interpreted with little depth (for example, exchange of information, consultation), the public project Manobras no Porto serves to analyze: 1) how a broad and deep concept of participation can be implemented in practice (and under what circumstances can it be successful) and 2) what kind of results can be achieved. In addition to the potential practical interest, the article also aims to contribute to deepening the debate on cultural mapping. The analysis clearly shows that participation involves a large and complex set of motivations and abilities, and that understanding how cultural mapping projects are developed (and their impact on the territory) requires that they be understood as exercises of negotiation between the agents involved.
\end{abstract}

Keywords: cultural mapping, participation, governance, urban development, 'Manobras no Porto' project, Portugal

Résumé : Cet article discute de l'importance de la cartographie culturelle en tant que stratégie de développement urbain. En particulier, cet article analyse en quoi la mission participative de la cartographie culturelle peut être opérationnalisée. De plus, cet article prend une distance visà-vis des projets où la participation revêt un caractère strictement rhétorique ou symbolique se limitant à l'échange d'information ou à la consultation et ce, afin d'aborder des expériences où la participation s'exprime de manière plus complète. Afin d'élaborer sur la question, le propos s'appuie sur le projet de Manobras no Porto afin d'analyser : 1) la portée et la profondeur des méthodes de participatives ainsi que les circonstances qui participent à leur succès; 2) le type de résultants auquel l'on peut s'attendre. En plus des enjeux pratiques soulevés par cette étude, cet article vise à contribuer à l'approfondissement théorique de la question de la cartographie culturelle. L'analyse met clairement en évidence la diversité des aptitudes et motivations découlant de la participation à la cartographie culturelle. Il devient alors essentiel que le sens et les enjeux de la cartographie culturelle soient négociés par les acteurs concernés.

Patrícia Romeiro is a Postdoctoral Researcher at the CEGOT Research Centre, University of Porto, Portugal. Her research interests concern the cultural/creative activities in the context of urban/regional development and innovation. E-mail: patriciaromeiro@yahoo.com.

Culture and Local Governance / Culture et gouvernance locale, vol. 5, no. 1-2, 2015. ISSN 1911-7469

(c) Centre on Governance, University of Ottawa, 55 Laurier Avenue East, Ottawa, Ontario, Canada K1N 6N5 
Mots clé : cartographie culturelle, participation, gouvernance, développement urbain, projet 'Manobras no Porto', Portugal

\section{Introduction}

In recent decades, there has been a growing interest in cultural mapping worldwide as a methodology for regional and local development (e.g., Canada, U.K., Australia), specifically within cultural planning, cultural tourism, community/cultural development, and the development of creative industries. It has been used for policymaking at regional and local levels (e.g., Creative City Network of Canada), recommended by organizations such as UNESCO as a tool for safeguarding cultural diversity, and for research-action purposes (e.g., Cultural Asset Mapping in Regional Australia). Alongside this enthusiasm, there is an increasing amount of documentation on theoretical and methodological issues related to cultural mapping.

A general definition of cultural mapping describes it as a tool to identify and document local cultural resources (Clark et al. 1995; Stewart 2007). The literature tends to emphasize the advantages of cultural mapping, in contrast with other tools (e.g., cultural survey, inventory), in relation to the kind of information surveyed and the process.

In regards to the first advantage, cultural mapping includes both tangible (e.g., physical spaces, organizations, programs, natural heritage, and cultural heritage) and intangible resources (e.g., memories, narratives, values, relationships, rituals, skills, and practices) (Clark et al. 1995; Stewart 2007). Moreover, by looking at "cultural resources, networks, links and patterns of usage of a given community or group" (Stewart 2007, p. 8), cultural mapping has the ability to capture the complexity and the dynamics of connections between the material and non-material dimensions of culture. Moving away from a static and simplistic concept of culture, this tool serves to integrate elements that help define communities in terms of cultural identity, vitality, sense of place, and quality of life (Lee \& Gilmore 2012; Stewart 2007).

With respect to the second benefit, in much of the literature on cultural mapping, the 'community' assumes a key role during the process (cultural assets are best recognized by its members) and as the primary beneficiary of that process (e.g., Clark et al. 1995; Lee \& Gilmore 2012; Moore \& Borrup 2012; Stewart 2007). Moreover, some writers advocate that "the process itself of getting people together to share resources and stories - and the working relationships that can result - have equal or greater value than the map or inventory of assets that might be generated" (Moore \& Borrup 2012, p. 147).

Despite the central role that the community plays in the cultural mapping process, to date, little attention has been paid to the participatory element. Studies on cultural mapping tend to be based on toolkits (e.g., Stewart 2007) or focused on examples of completed projects that do not offer any insight into the process (e.g., Lee \& Gilmore 2012). While it is true that very often cultural mapping projects in practice do not develop all their participatory potential, "in favour of simplistic surveys which promote inter-city competition through image management" (Lee \& Gilmore 2012, p. 8), there is a need for reflexive analysis on this topic.

This article addresses how broader and deeper levels of participation in cultural mapping projects can be stimulated. Based on a case study of a cultural mapping project called Manobras no 
Porto (MnP), carried out in the Historic Centre of Porto (Portugal), the article pays particular attention to the participatory process and especially to how discourses about participatory cultural mapping projects are transformed into participatory practices. It begins by discussing the circumstances within which the MnP was able to develop participatory practices and the results that were achieved in terms of urban development. Then the article reviews the relevant literature on the role of participation in contemporary urban development, in which culture occupies a prominent place. Next, it presents methodological questions related to the study, and in the fourth section, the case study is presented and analyzed. The final section summarizes some of the main ideas, highlighting the conditions that make it possible to have broader and deeper participation in cultural mapping projects.

\section{Participation, culture, and urban development}

Participation is one of the core concepts in urban policy discourses today. No longer limited to more alternative and underground initiatives, as it was in the 1950s, it was in the 1990s that the concept of participation attracted greater visibility and popularity. Chambers (1994) alludes to a "renaissance" of the concept as a result of changes in development thinking and practice (p. 1). The popularity of the participation concept is thus closely associated with a change in how we understand politics, where the concept of governance alludes to the diversification of governing mechanisms in response to the greater complexity of the contemporary city (Coaffee \& Healey 2003; Cornwall 2003).

As a form of regulation, governance refers to forms and practices of management by negotiation and dispersed networks, rather than by traditional methods of hierarchical command and control (Coaffee \& Healey 2003). Participation can thus be defined as a process through which multiple actors influence and share control over development initiatives and the decisions and resources that affect them. As noted by Pedro Ibarra (2007), participation by invitation (in spaces conceded by institutions) mixes and coexists with other kinds of participatory practices that occur by 'irruption' (when people take and occupy spaces, to raise their voice).

In recent decades, cities worldwide have witnessed a gradual shift in understanding about the instruments and objectives of regeneration and development policies. With culture now considered a catalytic resource for economic and social development, the involvement of different urban agents in the development process has assumed a more prominent place in urban strategies (Evans 2005). International organizations like UNESCO have progressively emphasized the advantages associated with participatory processes in culture and, in particular, their contribution to protecting and promoting cultural diversity and sustainable development (see, for example, UNESCO 2012). Participatory approaches can challenge the conventional expertise typical of top-down development interventions by enabling people to articulate their own identities and their own concerns and thus to value autochthonous forms of self-representation, knowledge, and expression (Coaffee \& Healey 2003; Cornwall 2003). In the language of participatory development, 'stakeholders' have gradually taken the place of the former 'beneficiaries', and development practitioners no longer play the role of experts, but rather of facilitators and enablers (Coaffee \& Healey 2003).

Several studies, however, have shown the limits of participatory cultural events (Carey \& Sutton 2004; Bailey et al. 2004). A review of this literature identifies causes that can be grouped as 
follows: 1) honesty of the proposal, 2) failure in creating the framework where pre-existing power relations can be challenged, and 3) demotivation of the intended beneficiaries. These limitations and issues shine attention on weaker versions of 'participation' more generally. For example, apart from understanding participation as an empowering process, Chambers (1994) discusses two additional uses of the concept: as "cosmetic labelling, to look good" and as "co-opting practice, to secure local action and resources" (p. 1), highlighting the rhetoric associated with the concept. Cooke \& Kothari (2001) also point out that not all initiatives are created with the intention of fulfilling the promises of empowerment, but to ensure pre-shaped development agendas.

Even projects that appear transformative may end up merely reinforcing the status quo. In their review of the state of the art on arts and culture as an urban and regional development tool, Markusen \& Gadwa (2010) present a framework for understanding how cultural planning operates at the local level, examining variations in public sector cultural capacity and implementation, as well as in the range and differing interests and power of stakeholders. They conclude that decisionmakers, in general, fail to build decision-making frameworks where artists, smaller-scale arts organizations, and a multiplicity of distinctive cultural communities can participate. As a result, they say, cultural planning at the regional and local level becomes captive of particular real estate interests, cultural industries, and cultural elites (Markusen \& Gadwa 2010). So, under which circumstances can different forms of participation create either opportunities for further participation or entrench and reproduce existing power relations? As "sharing through participation does not necessarily mean sharing in power" (White 1996, p. 6), at times the discourse of participation can obscure as well as challenge inequalities of resources and power (White 1996; Gaventa \& Cornwall 2006). In this sense, in addition to a necessary predisposition to implement true participatory processes, it is also necessary to create a framework that guarantees a certain equality of conditions for the different types of agents. Recent academic literature on participatory processes has highlighted the importance of mechanisms to facilitate the participation of individual citizens, in addition to those related to organized groups, reflecting current changes in participatory practices (see, for example, Kahane et al. 2013).

Finally, the best intentions can meet a dead end when supposed beneficiaries choose not to participate. In fact, many participatory actions experience low participation levels. For Cooke \& Kothari (2001), this is partly due to the fact that the relationship between government and local populations is often characterized by low confidence levels, and by conflict and resentment. In the same vein, Jochum et al. (2005) argue that in many cases citizens are affected by previous experience of interventions with little perceived benefit, generating feelings of distrust, fatigue, or disappointment.

The literature suggests that participation, roughly defined as the possibility of involvement in a collective project, is a complex practice. In this sense, it seems important to better understand the motivations for participating and what kind of mechanisms are most often used to make effective participation possible. Participation not only has a civic-public dimension but also a social dimension related to an individual's associational activities in both formal and informal contexts. As Jochum et al. (2005) note, people "are motivated by their faith or values; their sense of community, whether of interest or place; or simply a desire for friendship and conviviality” (p. 33). 
There are different mechanisms to create space for, or to facilitate, community participation in territorial development initiatives. Several authors have developed typologies that explore these different mechanisms and their implications for the quality and/or the 'depth' of participation (e.g., Arnstein 1969; Burns et al. 1994; Wilcox 1994). The spectrum includes mechanisms that range from participation techniques that involve the provision of information (e.g., through websites and factsheets), which is little more than information sharing, to individual contributions to decisionmaking (e.g., citizens' juries) that lead to deeper levels of participation and to empowerment.

Wilcox's typology (1994) defines five stages of participation: 1) information, where people are told what is planned; 2) consultation, which offers some options and listens to feedback; 3) deciding together, which encourages additional options and ideas and provides opportunities for joint decision-making; 4) acting together, where different interest groups decide together on what is best and on the partnership needed to carry it out; and 5) supporting independent community interests, where local groups or organizations are offered funds, advice, and other support to develop their own agendas within specific guidelines. This model is grounded in the desire to collaborate and work in partnership with a number of stakeholders and is informed by the understanding that "working together allows everyone to achieve more than they could on their own" (Wilcox 1994, p. 2). This model also highlights that different degrees of control (over information, the allocation of funding, or the setting of agendas) are the result of power and depend on who has information and/or money. As Wilcox (1994) notes, "the initiator is in a strong position to decide how much or how little control to allow to others" (p. 2).

Therefore, it is important to analyze to what extent it is possible to develop in practice: 1) mechanisms to stimulate broader levels of participation, and 2) participatory frameworks in which a more balanced distribution of 'control' and 'power' among those who want to participate can be achieved. In other words, how can deeper levels of participation in projects be obtained?

\section{Methodology}

The literature on cultural mapping says that it involves the identification and documentation of local cultural resources that make a community unique. After these activities, cultural mapping involves the development of community activities or projects, to record, conserve, and use these elements (Clark et al. 1995; Stewart 2007).

In the last few years, there has been a growing volume of academic literature on cultural mapping projects; however, to date, little attention has been paid to the participatory element. Focusing on this issue from a project management point of view, this study is particularly interested in analyzing how, in practice, cultural mapping projects can create frameworks that favour more diverse and deeper levels of participation.

The proposed analytical framework focuses on three key processes related to the organization and management of the MnP cultural mapping project. In the initial stage - project design - the territory of intervention, the mission, and the organizational structure were first defined. The two following stages - mobilization and negotiation - occurred throughout the project. Mobilization was understood as the process of engaging individual citizens and organized groups, and encouraging them to participate in the MnP project. Negotiation was defined as the dialogue between two or more agents, intended to resolve points of difference or to craft outcomes to satisfy 
collective interests. The analysis of these two processes served to better understand how the participatory character of the $\mathrm{MnP}$ cultural mapping project was operationalized. The analytical framework also includes an analysis of the impacts of the MnP's participatory framework on participation (quantity, diversity, and depth of participation) and on cultural mapping outcomes and outputs related to urban development (see Figure 1).
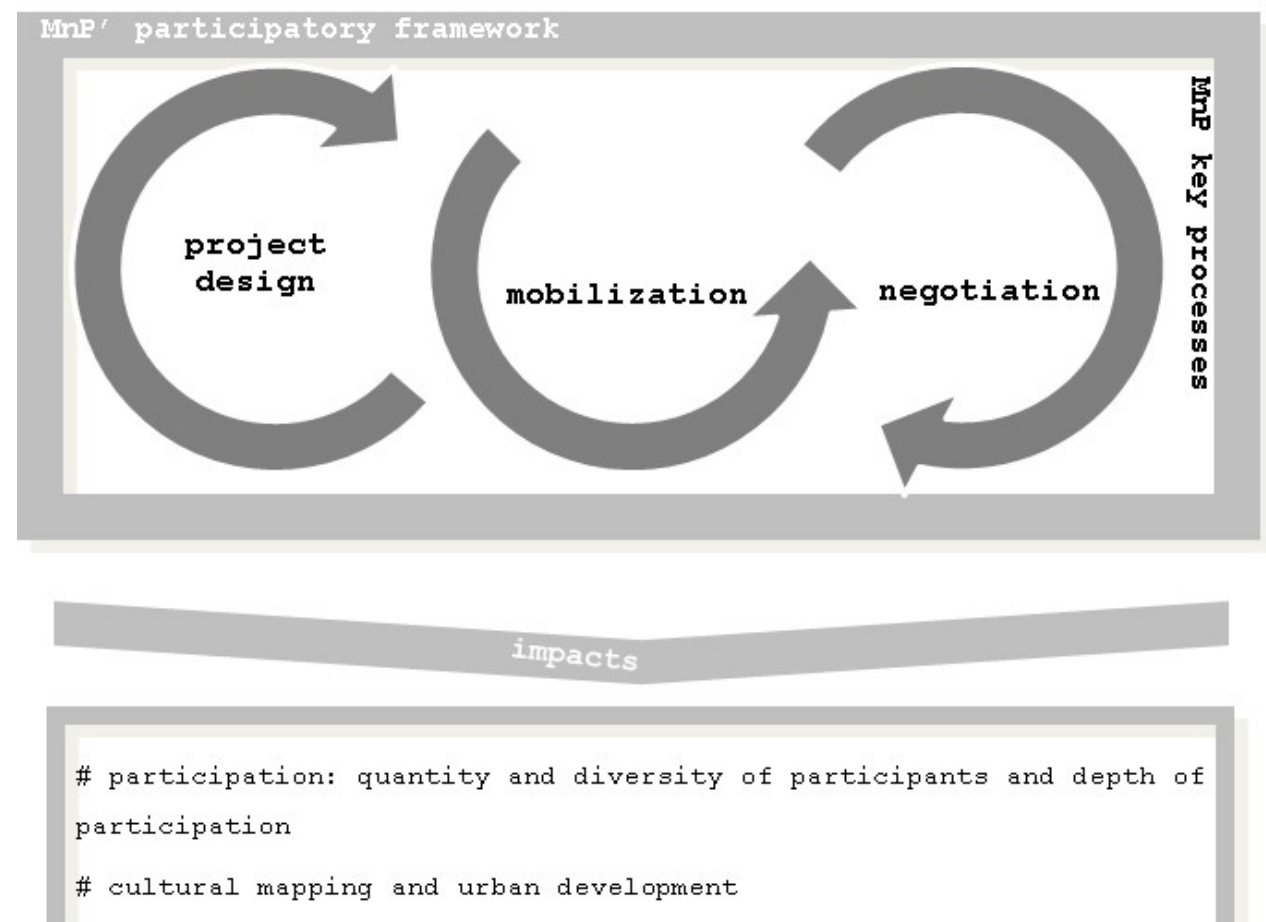

Figure 1. Analytical framework of the MnP cultural mapping project

The results presented here are based on a collection of qualitative and quantitative data gathered through semi-structured interviews, participant observation, and secondary sources of information, such as reports and planning documents, which was carried out continuously between 2011 and 2013. The main objective was to collect data that could serve to analyze and reflect on the evolution of the relationship between the people, actions, and spaces promoted within the MnP, in the Historic Centre of Porto. The data refer to the processes, as well as to the outcomes and outputs, related both to the macro project ( $\mathrm{MnP}$ macro coordination) and to the micro-actions developed by individuals and organized groups.

It should be mentioned that the researcher was directly involved in the MnP project (monitoring and evaluation activities), assuming the double role of participant and observer. Distancing myself from a positivist approach, a research strategy based on proximity and collaboration with the object of study - "reflexivity complicit" as Marcus (2001) called it - was seen as a strength for this study (e.g., direct and constant access to information at all levels of project implementation). 


\section{Manobras no Porto Project}

Manobras no Porto project (MnP) was a multidimensional project that aimed to intervene in the present and future of the Historic Centre of Porto, Portugal, through initiatives of survey and creation. Developed continuously between 2011 and 2012, it was a platform for various cultural actions and events intended to regenerate immaterial heritage. Having the Historic Centre of Porto as not only context but also content, the MnP project defined the starting point for all its actions as the identification and mapping of its resources (e.g., people, knowledge, institutions, spaces, legends).

$\mathrm{MnP}$ was the outcome of the application "PORTO 2.0 - Festival of the Moving City," submitted in 2009 to the regional program ON.2 - O Novo Norte by Porto Lazer (a public company managed by the Porto City Council), and coordinated overall by Opium (a company devoted to the creative industries sector). The regional funding program considered the organization of large-scale events as a key element in the development of the regional agenda for the creative industries. The submitted project's unusual merit (relevance and ambition) - transcending a general tendency towards a uniformity of formats, territorial disengagement, and a focus on exhibition - was acknowledged by the CCDRN. ${ }^{2}$ The project mobilized a global investment of 2,153,380.80 euros.

\section{Project design}

The MnP defined the Historic Centre of Porto as ground for its continued work of exploration, mapping, discussion, and creation. Rich in memories, discourses, and community values, the Historic Centre of Porto $^{3}$ was identified as a place of potentials (e.g., relational, symbolic) whose realization seems to be continually postponed. As a result, buildings are deteriorating, residents are leaving, and activities are being abandoned. While the Historic Centre of Porto is both a recognized heritage centre of the city (and of humanity), it does not seem to radiate life outside its borders, leaving its persons, activities, and culture confined to its own territory. These dynamics have gradually worsened over recent decades and coincide with other more recent ones. Keeping pace with global trends, the Historic Centre of Porto has been increasingly subject to tourism and real estate development and commercial activities. Restructuring of the Historic Centre of Porto is challenged by the confrontation between social memories and practices in decline and new uses that ignore, reinvent, or devastate its culture (Manobras no Porto 2013).

Based on this analysis, the $\mathrm{MnP}$ set as its mission to support a continuous work of cultural mapping in, and on, the Historic Centre of Porto over two cycles. In each twelve-month cycle, some 'involvement projects' (less visible in-depth work within the territory) were to be developed, where agent-leaders would work collaboratively with other local actors (e.g., creatives, citizens, NGOs, businesses, universities). As a complement to this ongoing action, a more visible 'low involvement'

\footnotetext{
${ }^{1}$ ON.2 - O Novo Norte is an operational program within the scope of the National Strategic Reference Framework (QREN) 2007-2013.

${ }^{2}$ Commission for the Coordination and Regional Development of the Northern Region (CCDRN), in charge of ON.2 - O Novo Norte (regional programme) management.

${ }^{3}$ The Historic Centre of Porto is the oldest area of the city and is composed of four administrative territories: Sé, Vitória, São Nicolau, and Miragaia.
} 
program was planned in the form of a festival named Dias de Manobras (Days of Maneuvers), which was scheduled to take place between September and October.

The MnP acted as a meeting platform for various urban agents, built around their micro cultural mapping projects, and supported by a network. In the design of the $\mathrm{MnP}$ ecosystem, the coordination structure (e.g., communication, monitoring, financial) consisted of a small and flexible team, which was the responsibility of the company that designed the project in cooperation with Porto Lazer. Cultural and creative agents - both individuals and organized groups - led the cultural mapping process by presenting and developing cultural mapping micro-actions that aimed to encourage participation by other creative, educational, social, and political agents. An Advisory Board was also established, comprising six experts from different creative fields, to provide macroanalysis and to periodically discuss the project.

\section{Mobilization process}

The MnP project foresaw an increasing participation (individual and collective) over the two years (2011 and 2012) through a continuous mobilization at different scales and using different mechanisms. Although continuous, the mobilization was more intensive in two periods in each of the MnP's cycles. Through the Call for Involvement, launched in the winter, actions of longer duration rooted within the territory were collected. Through an Open Call, launched in the early summer, the MnP encouraged experimental and celebratory actions that were shorter and less engaged with the territory.

Although the utopian idea of the $\mathrm{MnP}$ was to integrate all the city agents, it was thought essential to determine, from the outset, a realistic field of action as a critical element for the project. To this end, the project established (in 2011) mobilizing questions - What is this city? What city does it want to be? - and a set of lines of action where the different proposals could fit into. The coordination team and the Advisory Council wanted these questions and lines of action to simultaneously reflect the dilemmas of the territory, communicate the mission, and be provocative and mobilizing.

The potential partners for the calls were mobilized in various ways. In the first call (2011), when the MnP was still not well known, several presentations on the project were made to cultural and creative agents, encouraging them to submit actions. At the end of the first year, the coordination team concluded that the $\mathrm{MnP}$ had been able to involve agents with less visibility, but who had more experience in cultural mapping projects, rather than more passive agents (e.g., both large institutions and smaller groups). This evidence led to the creation of four categories of participation for the second cycle, reflecting different levels of engagement (e.g., participation in workshops, provider of specific resources or knowledge, leadership).

The macro-level of mobilization (the MnP's structuring actions) was driven mainly by the coordination team and was developed in parallel with efforts by the proponents of each of the 190 micro-scale actions at the neighbourhood and street levels. For example, in the Ateliers do Porto 
(Craftsman Workshops of Porto) $^{4}$ and Porto Sonoro (The Sounds of Porto) ${ }^{5}$ actions, mobilization was based on 'knocking door-to-door' in the neighbourhoods. The Peregrinações (Pilgrimages) ${ }^{6}$ action, mediated by the MnP coordination team, approached participants through a local social centre which hosted it in one of its spaces, from where it progressively spread out to other connection nodes, both individual and institutional. Thus each micro-action developed its own methodology of mobilization (and production), building its complex network in very different ways.

The MnP acted as a collective platform for mapping, reflection, and action around a mission. The work of the coordinating team consisted mainly in providing the proper conditions so that everybody who wanted to participate could do so. One of the challenges of this platform was to understand the role, skills, resources, availability, permanence, and expectations of each of the actors, recognizing their differences, and understanding how they could be coordinated in operational networks.

\section{Negotiation process}

Negotiation was very present, implicitly and explicitly, throughout the project, as a consequence of the network structure and its experimental nature. Negotiation was encouraged and occurred, although not homogeneously, between all the action scales of the project (e.g., between promoters, coordinators, and leaders of actions), between the same scale of action and a more micro level, and within each individual action. This vocation became clear at an early stage of the MnP, during the operationalization of the mission of the project. While seeking broad participation, the coordination team also made it clear that it sought agents with an idea and a will to act, and who were also predisposed to negotiate.

The processes of negotiation between the coordination team and the agents who led actions in the $\mathrm{MnP}$ were continuous, especially in daily management of the actions on the ground (e.g., spaces, relationships, actions, times) and in the management of bureaucracies. The balance between confrontation and debate of ideas and the progress of the shared actions was mainly achieved through the trust that was established. Given that there was no previous relationship between the coordination team and the leaders of actions, trust was gradually built in spaces that were created and where different expectations, difficulties, and mistakes could be discussed constructively. This trust was generated and legitimized (or not) based on the response of each agent to the operationalization of the MnP's mission (i.e., legitimacy by action). Such commitments were generated primarily on an informal basis, resulting from the partnerships between agents and the alignment of actions with the mission and objectives of the $\mathrm{MnP}$, and only afterwards were formalized.

\footnotetext{
${ }^{4}$ Starting from a map of the city's craftsman workshops, the 'Craftsman Workshops of Porto' action challenged a group of designers to use the unique skills of these craftsmen in the design and production of new objects that could take advantage of their barely visible capabilities.

${ }^{5}$ The main focus of 'The Sounds of Porto' was to reflect the sonic identity of the city, both in terms of the mapping of its sounds, and of the artistic and scientific reflections and transformations of its sound archive.

6 'Pilgrimages' was developed as an action of participatory mapping and of artistic creation, having as raw material the flows of people and beliefs in the Vitória neighbourhood.
} 
An example of this occurred during the process of selecting actions under the Involvement Call in 2012. After a participatory evaluation of the actions developed under the $2011 \mathrm{call}^{7}$, an action proposed by a creative collective, renowned in the city, was not approved because of its poor performance and opportunistic attitude. On the other hand, a group of creatives with a small action in 2011's Open Call were encouraged to play a more committed role in 2012 due to their high performance and willingness to strengthen their action and skills. This selection was based on the identification of actions that, actually or potentially, showed greater capacity to accomplish the mission of the $\mathrm{MnP}$ through, for example, the quality of the agents involved, degree of commitment, or quality of the proposal.

Negotiation between the coordination team and the funder also occurred throughout the project, highlighting the constant attempt to create balance between the institutional practices of the latter and the experimental nature of the $\mathrm{MnP}$, as interpreted and developed both by coordination team and by the agents on the ground. For example, negotiation was required due to different visions about the visibility and exposure of the actions on the ground. The coordination team had to negotiate a balance between the independence associated with creative processes and the need for public transparency regarding the project's actions and their results. Another example of the different views and practices that required negotiation related to obtaining the required public authorizations, which were subject to strict bureaucratic procedures and deadlines.

At the micro-scale of actions developed on the ground, negotiation processes were particularly intense with regard to questions related to the use and ownership of physical spaces and everyday practices. These negotiations occurred not only between the promoters of the action and the participants, but also between these actors and other users of the public space where each action was developed.

\section{Results}

Participation in the MnP was significant, both in the number and the type of urban actors involved. Over two years, 190 creative actions were carried out through both the Call for Involvement and the Open Call, and about 7,000 people participated in them directly. A total of 209 agents with different motivations and visibility in the city, feeling challenged by the MnP's proposal, presented an action. These included artists and creative businesses, cultural institutions, and education and research institutions). And buildings, streets, and squares were occupied by 300,000 people, attracted by public presentations during the Dias de Manobras.

The $\mathrm{MnP}$ also created space to experiment with new forms of relationships, challenging practices of existing power and legitimacy, through activities of exploration and creation based on the intangible cultural resources of the Historic Centre of Porto. Although the mobilization of the Historic Centre of Porto's population has not always been easy - feelings of abandonment by public bodies, passivity, and resignation to the situation in which they live are the norm - the participants gradually became actors through the 'involvement projects'. The continued development actions

\footnotetext{
${ }^{7}$ Each action of the Involvement Call was self-assessed by its leaders and critically analyzed by the coordination team. These were then analyzed and discussed between the two parties (including items such as the mission in 2011, the 2011 audit, and challenges for 2012).
} 
with meaning and value to the residents enabled ties to be built based on mutual recognition of capabilities and on trust.

The MnP invited everyone to participate in activities with different levels of involvement, ranging from low-involvement ones (e.g., attendance at events, consultation, and participation in workshops) to those involving greater depth and responsibility (e.g., leadership actions, mobilization). Through these mechanisms, the project was able to generate not only audiences, but also networks of people who met for weeks or months, and were linked with research processes and network creation.

Although participation was significant, the development of $\mathrm{MnP}$ faced obstacles to mobilization and involvement linked to the routines of each cultural and creative agent (e.g., their times, spaces, and relationships). The decision to become involved was often felt, at first, as an internal negotiation: for example, between the effort of moving towards unknown territory and the appeal of a project with a structure, resources, and visibility in the city; or between a personal and professional attitude of independence and participation in a collective project of a politicalinstitutional nature.

By exploring and creating creative activism actions based on the cultural resources of the Historic Centre of Porto, the MnP was promoting the revitalization of this area. In some cases it facilitated a better understanding of the resources of the territory. In other cases, it allowed certain resources to be made available. In yet others, it helped them to be reinterpreted and valued, providing a new visibility. Some 268 cultural and creative products in music, performance, visual arts, design, and video and several creative companies resulted from the two project cycles. ${ }^{8}$ The project was also continuously documented, and the City's archives now have 16,416 mapping documents available for consultation (e.g., photos, videos, audio, and texts).

\section{Conclusion}

The literature unanimously considers that cultural mapping is an "effective tool for development" (Stewart 2007, p. 7) and that one of its benefits is to be a vehicle for community engagement (Gibson 2010; Lee \& Gilmore 2012; Stewart 2007). However, participation in cultural mapping has not been sufficiently addressed in previous studies. Communities, and participatory projects, are often referred to in working documents and scientific studies as self-evident, unproblematic, and homogeneous entities.

By analyzing a project which intended to put into practice its vocation as a participatory process, this article explores how the discourse associated with participatory cultural mapping can

\footnotetext{
${ }^{8}$ Some examples: 1) an audio archive of the sound heritage of Porto (containing a sound map, a list of sounds by categories, and software to create musical compositions), as the result of the action Porto Sonoro (The Sounds of Porto); 2) in addition to the construction and presentation of the play, Pilgrimages, the 'Pilgrimages' action created a documentary and a book focused on its process, as well as the Community Theatre of Vitória; 3) a radio station, resulting from the action Rádio Manobras (Radio Manoeuvres); and 4) an itinerant publisher of spontaneous publications, as the result of the action Cachorros Quentes Editora Ambulante (Hot Dogs Itinerant Publisher), which moved across the Historic Centre of Porto in a hot dog cart that served as a workspace and an exchange point of small publications of local stories.
} 
be operationalized, and how a broader and deeper level of participation can affect cultural mapping projects and, consequently, have an impact on urban development.

The MnP was a multidimensional project-platform for a grassroots movement, developed by agents from different urban 'systems' (e.g., citizens, cultural, educational, and social) and strongly rooted in networking, which was coordinated and funded by regional and local public administrations. It aimed to intervene in the present and future of the Historic Centre of Porto through identification, analysis, and creative cultural mapping actions intended to regenerate its immaterial heritage.

Analysis of the MnP cultural mapping project shows that it is possible, and desirable, to bring together different communities directly or indirectly involved in urban development (e.g., politicians, development agencies, artists, companies, citizens). The case study also showed that it is possible to develop deeper levels of participation through the design, development, and leadership of cultural mapping actions. However, one must bear in mind that urban agents have multiple motivations (often overlapping) and that they are not equally willing or interested in challenging the status quo of power or relations. The challenges associated with participation affect not only politicians (most often analyzed in the literature) but also citizens, universities, and other organizations.

Bringing participation into the core of a cultural mapping project involves creating spaces or contexts where urban agents can experience new forms of legitimacy and build trust relationships, but it is also necessary to develop activities with different levels of involvement, depending on agents' motivation and availability. One lesson from the MnP points toward the crucial role of mediation undertaken by the coordination team - combining cultural and creative skills and the ability to have an institutional influence. We also emphasize the quality of the MnP mission - clear, broad-ranging, and utopian but, at the same time, pragmatic and action-oriented. This was reinforced by the communication strategy, which was based on colloquial language and on local culture, with a strong visual component that demystified the institutional language. This made it possible to overcome certain unfavourable starting conditions, including a pre-existing climate of disengagement and distrust between the local public administration and a substantial part of the cultural and creative community, as well as the citizens of the Historic Centre of Porto.

In addition to acting as a catalyst and a vehicle to bring together different interests and spheres of knowledge, the $\mathrm{MnP}$ cultural mapping project yielded results that reflect a broader and more diverse notion of culture. Besides the material and measurable results, such as numbers of participants, products, and spaces, the $\mathrm{MnP}$ was a platform where new spaces of governance between urban agents and political agents were explored. $\mathrm{MnP}$ also contributed to place-making and to strengthening and updating the area's identity. When neo-liberal public interventions and their territorial consequences (e.g., tourist attraction, gentrification) were intensified in the Historic Centre of Porto, the MnP acted as a space of resistance and created meanings that were embedded in new images and narratives, new products and services, and alternative socio-spatial relations. 


\section{Acknowledgement}

The author received financial support from the Fundação para a Ciência e a Tecnologia (Portuguese Foundation for Science and Technology) within the project PEST-OE/SADG/UI4084/2014 and the grant contract SFRH/BPD/77963/2011 for the research and authorship of this article.

\section{References}

Arnstein, S.R. (1969). A ladder of citizen participation, Journal of the American Institute of Planners, 35(4): 216-224.

Bailey, B., Miles, S. \& Stark, P. (2004). Culture-led urban regeneration and the revitalisation of identities in Newcastle, Gateshead and the North East of England. International Journal of Cultural Policy, 10(1): 47-65.

Burns, D., Hambleton, R. \& Hoggett, P. (1994). The Politics of Decentralization: Revitalising Local Democracy. London: MacMillan.

Carey, P. \& Sutton, S. (2004). Community development through participatory arts: Lessons learned from a community arts and regeneration project in South Liverpool. Community Development Journal, 39(2): 123-134.

Chambers, R. (1994). Paradigm shifts and the practice of participatory research and development. IDS working paper, no. 2. http://opendocs.ids.ac.uk/opendocs/bitstream/handle/123456789/1761/rc81a.pdf? sequence $=10$ [4 May 2014]

Clark, I., Sutherland, J. \& Young, G. (1995). Mapping culture - a guide for cultural and economic development in communities. Communication presented at the Cultural Mapping Symposium \& Workshop, Adelaide, Australia. www.unescobkk.org/culture/diversity/culturalmapping/ [4 May 2014].

Coaffee, J. \& Healey, P. (2003). 'My voice: My place': Tracking transformations in urban governance. Urban Studies, 40(10): 1979-1999.

Cooke, B. \& Kothari, U. (2001). The Tyranny of Participation. London: Zed Books.

Cornwall, A. (2002). Locating citizen participation. IDS Bulletin, 33(2): 49-58.

Cornwall, A. (2003). Whose voices? Whose choices? Reflections on gender and participatory development. World Development, 31(8): 1325-1342.

Gaventa, J. \& Cornwall, A. (2006). Challenging the boundaries of the possible: Participation, knowledge and power. Institute of Development Studies, 37: 122-128.

Gibson, C.R. (2010). Place making: Mapping culture, creating places: collisions of science and art. LocalGlobal: Identity, Security, Community, 7: 66-83.

Ibarra, P. (2007). Participación y poder: de la legitimación al conflicto. In I. Ahedo Gurrutxaga \& P. Ibarra Güel (eds.), Democracia Participativa y Desarrollo Urbano (pp. 33-53). Madrid: Dykinson.

Jochum, V., Pratten, B. \& Wilding, K. (2005). Civil Renewal and Active Citizenship: A Guide to the Debate. London: NCVO.

Kahane, D., Loptson, K., Herriman, J. \& Hardy, M. (2013). Stakeholder and citizen roles in public deliberation. Journal of Public Deliberation, 9(2), Article 2. www.publicdeliberation.net/jpd/vo19/ iss2/art2 [19 November 2015]

Lee, D. \& Gilmore, A. (2012). Mapping cultural assets and evaluating significance: Theory, methodology and practice. Cultural Trends, 21(1): 3-28.

Rangel, A., Canha, A. \& Pedrosa, A. (eds.) (2013). Manobras no Porto. Que cidade é esta? Que cidade pode ser esta? PortoLazer: Porto. http://futureplaces.up.pt/manobras/livro_manobras.pdf [4 May 2014] 
Marcus, G.E. (1995). Ethnography in/of the world system: The emergence of multi-sited ethnography. Annual Review of Anthropology, 24: 95-117.

Markusen, A. \& Gadwa, A. (2010). Arts and culture in urban or regional planning: A review and research agenda. Journal of Planning Education and Research, 29(3): 379-391.

Moore, S. \& Borrup, T. (2012). Cultural mapping. In D. Borwick (ed.), Building Communities, Not Audiences: The Future of the Arts in the United States (pp. 146-156). Winston-Salem, NC: ArtsEngage.

Stewart, S. (2007). Cultural Mapping Toolkit. Vancouver: Creative City Network of Canada \& 2010 Legacies Now. www.creativecity.ca/database/files/library/cultural_mapping_toolkit.pdf [4 May 2014]

UNESCO. (2012). Measuring Cultural Participation. UNESCO Framework for Cultural Statistics Handbook No. 2.

White, S. (1996). Depoliticising development: The uses and abuses of participation. Development in Practice, 6: 6-15.

Wilcox, D. (1994). Community Participation and Empowerment: Putting Theory into Practice. York: Joseph Rowntree Foundation. 